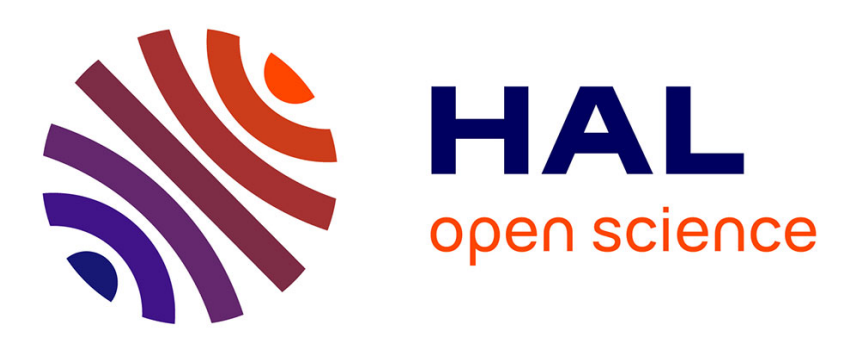

\title{
Microtubule stabilizer ameliorates synaptic function and behavior in a mouse model for schizophrenia.
}

Annie Andrieux, Paul A. Salin, Annie Schweitzer, Mélina Bégou, Bastien Pachoud, Philippe Brun, Sylvie Gory-Fauré, Pekka Kujala, Marie-Françoise Suaud-Chagny, Gerhard Höfle, et al.

\section{To cite this version:}

Annie Andrieux, Paul A. Salin, Annie Schweitzer, Mélina Bégou, Bastien Pachoud, et al.. Microtubule stabilizer ameliorates synaptic function and behavior in a mouse model for schizophrenia.. Biological Psychiatry, 2006, 60 (11), pp.1224-30. 10.1016/j.biopsych.2006.03.048 . inserm-00380045

\section{HAL Id: inserm-00380045 https://www.hal.inserm.fr/inserm-00380045}

Submitted on 7 May 2009

HAL is a multi-disciplinary open access archive for the deposit and dissemination of scientific research documents, whether they are published or not. The documents may come from teaching and research institutions in France or abroad, or from public or private research centers.
L'archive ouverte pluridisciplinaire HAL, est destinée au dépôt et à la diffusion de documents scientifiques de niveau recherche, publiés ou non, émanant des établissements d'enseignement et de recherche français ou étrangers, des laboratoires publics ou privés. 


\section{Microtubule Stabilizer Ameliorates Synaptic Function and Behavior in a Mouse Model}

\section{for Schizophrenia}

Annie Andrieux ${ }^{1 *}$, Paul Salin ${ }^{2 *}$, Annie Schweitzer ${ }^{1}$, Mélina Bégou ${ }^{3}$, Bastien Pachoud ${ }^{2}$,

Philippe Brun $^{3}$, Sylvie Gory-Fauré ${ }^{1}$, Pekka Kujala ${ }^{4}$, Marie-Francoise Suaud-Chagny ${ }^{3}$,

Gerhard Höfle ${ }^{5}$ and Didier Job ${ }^{1}$

${ }^{1}$ Laboratoire du Cytosquelette, INSERM U366, Département Réponse et Dynamique Cellulaire, CEA-Grenoble, 17 Rue des Martyrs, 38054 Grenoble, France.

${ }^{2}$ CNRS UMR5167, Faculté de Médecine Laennec, 69372 Lyon Cedex 08, France.

${ }^{3}$ INSERM; Institut Fédératif des Neurosciences de Lyon; UCBL; Laboratoire de Neuropharmacologie et Neurochimie, 8 avenue Rockefeller, 69373 Lyon Cedex 08, France.

${ }^{4}$ The Netherlands Cancer Institute, Plesmanlaan 121, 1066CX Amsterdam, The Netherlands.

${ }^{5}$ German Research Center for Biotechnology (GBF), Mascheroder Weg 1, D-38124 Braunschweig, Germany.

* These authors contributed equally to the work.

${ }^{\S}$ Correspondance: email: annie.andrieux@cea.fr

Phone: 33-438-782-148; fax: 33-438-785-057

Running head: Epothilone D in STOP-null mice

Key words: microtubule, synaptic plasticity, epothilone, STOP protein, schizophrenia

Number of words in text: 4489

Number of words in abstract: 199

Number of figures: 5

Number of tables: 0 


\section{Summary}

Background: Recent data suggest a role of cytoskeletal defects in schizophrenia. We have previously obtained an animal model which recapitulates features of schizophrenia, by disrupting in mice a gene coding for a microtubule-associated protein called STOP. STOP null mice display synaptic defects in glutamatergic neurons, hyper-dopaminergy and severe behavioral disorders. Synaptic and behavioral deficits are amended by neuroleptic treatment in STOP null mice, which provide an attractive model for test of new anti-psychotic agents. Here, we have examined the effects of a taxol related microtubule stabilizer, epothilone D. Methods: Mice were treated either with vehicle alone or with epothilone D. Treatment effects on synaptic function were assessed using electron-microscopy quantification of synaptic vesicle pools and electrophysiology in CA1 region of the hippocampus. Dopamine transmission was investigated using electro-chemical assays. Behavior was principally assessed using tests of maternal skills. Results: In STOP null mice, a treatment with epothilone D increases synaptic vesicle pools and ameliorates both short- and long-term forms of synaptic plasticity in glutamatergic neurons and has a dramatic beneficial effect on mouse behavior. Conclusions: A microtubule stabilizer can have a beneficial effect on synaptic function and on behavior, and this suggests new possibilities for the treatment of schizophrenia. 
Introduction: Schizophrenia is a common and debilitating mental illness that exacts considerable human and economic costs (Schultz and Andreasen 1999). The origin of schizophrenia is still debated but current data favor a model in which schizophrenia arises from defects in neuronal connectivity, principally caused by synaptic alterations (Mirnics et al 2001; Owen et al 2005a; Owen et al 2005b). Recently, the protein coded by a gene known to be disrupted in a familial form of schizophrenia (DISC1) has been characterized and shown to be involved in a variety of interactions with microtubule-related organelles or proteins (Callicott et al 2005; Morris et al 2003), suggesting that connectivity disorders in schizophrenia can result from cytoskeletal alterations. Consistent with this hypothesis, we have obtained a genetic animal model, which displays a set of behavioral alterations and of neurotransmission defects reminiscent of schizophrenic disorders, by disrupting in mice the STOP gene, which encodes a microtubule-associated protein (Stable Tubule Only Polypeptide, STOP protein)(Bosc et al 2003; Bosc et al 1996; Guillaud et al 1998). STOPnull mice have an apparently normal brain anatomy but display a dramatic depletion of synaptic vesicle pools and severe impairments of synaptic plasticity in hippocampal glutamatergic neurons, indicating defects in the glutamatergic transmission (Andrieux et al 2002). STOP null mice also exhibit hyper-dopaminergy in the limbic system (Brun et al 2005). Such neurotransmission defects are consistent with the association of hypoglutamatergy and of hyper-dopaminergy, currently considered to be a landmark of schizophrenia (Frankle et al 2003), and are associated in STOP null mice with severe behavioral deficits, including a fragmentation of spontaneous activity, hyper-locomotor activity, anxiety-related disorders, signs of severe social withdrawal, dramatic perturbations 
of maternal behavior and a dysfunction of sensory-gating mechanisms which is also observed in schizophrenic patients (Andrieux et al 2002; Fradley et al 2005).

Interestingly, behavioral and synaptic deficits in STOP null mice are specifically alleviated with neuroleptic treatments (Andrieux et al 2002; Brun et al 2005; Fradley et al 2005). Neuroleptics are modulators of neurotransmitter receptors, namely dopamine blockers, which have been discovered in the fifties and which are still the most active known compounds for the treatment of schizophrenia.

The possible involvement of microtubule dysfunction in schizophrenia suggests that it may be possible to amend schizophrenic disorders using microtubule drugs. Here, we have tested whether a microtubule drug could emulate neuroleptics in alleviating STOP-null mice deficits. We have used epothilone $\mathrm{D}$, a taxol-related compound, which interacts directly with tubulin to stabilize microtubules (Kolman 2004; Nettles et al 2004; Wang et al 2005). In contrast with taxol, epothilone $\mathrm{D}$ can cross the brain blood barrier and accumulate in brain tissues. At high doses, epothilone D blocks microtubule dynamics and thereby cell division, and is currently used in clinical trials for the treatment of various tumors (Wang et al 2005). In this study we find a dramatic beneficial effect of epothilone D on STOP null mice deficits at doses which are orders of magnitude lower than anti-mitotic doses (Wang et al 2005) and which have no obvious deleterious effects on mouse fertility, embryonic development or viability. Our data provide the first demonstration that a microtubule drug can have a beneficial effect on synaptic transmission and on behavior in an animal model displaying neuronal connectivity disorders, thereby opening new possibilities for the development of novel antipsychotic agents for the treatment of human mental diseases. 


\section{Methods}

\section{Cell culture and microtubule stability assay}

Hippocampal cell cultures were prepared as previously described (Dotti et al 1988). Briefly, hippocampi brain tissue from E18.5 mice were removed and digested in $0.25 \%$ trypsin in Hepes-buffered Hanks' balanced salt solution (HBSS) at $37^{\circ} \mathrm{C}$ for 15 minutes. After manual dissociation, cells were plated at a concentration of 5,000-15,000 cells/ $\mathrm{cm}^{2}$ on poly-L-lysine (Sigma) coated coverslips in DMEM - 10\% FBS. One hour after plating the medium was changed to DMEM containing B27 and N2 supplement (Invitrogen). After one week in cultures, neuronal cells were incubated with various amount of Epothilone D for 1 hour and either exposed to cold temperature $\left(45\right.$ minutes, $4^{\circ} \mathrm{C}$ ) or maintained at $37^{\circ} \mathrm{C}$. Cells were permeabilized in lysis buffer (30 mM Pipes, $1 \mathrm{mM}$ EGTA, $1 \mathrm{mM} \mathrm{MgCl} 2,10 \%$ glycerol, 0.1\% Triton X-100, pH 6.75) for 1 minute, and processed for immunofluorescence. Cells were fixed for 6 minutes with cold methanol and incubated with mAb against $\alpha$-tubulin (TUB2.1) diluted 1/100 (Sigma) for 45 minutes in PBS - Tween $0.5 \%$ and with secondary antibodies for 40 minutes. Cells were analyzed with an inverted microscope Axioscop 50 (Zeiss) controlled by Metaview (Universal Imaging, Downingtown, PA). Images were digitalized using a Coolsnap ES camera (Roper Scientific).

\section{Drug administration}

For long-term neuroleptics treatment, mice were subjected to daily administration of a combination of haloperidol and chlorpromazine $(0.5 \mathrm{mg} / \mathrm{day} / \mathrm{kg}$ and $5 \mathrm{mg} / \mathrm{day} / \mathrm{kg}$, respectively), for 3 months, starting at weaning, in the drinking water (Andrieux et al 2002). Epothilone D and epothilone B were provided by the GBF (Braunschweig, Germany) (Hardt et al 2001). Epothilone D was injected intra-peritoneally, once a week, at doses varying from 3 to $0.03 \mathrm{mg} / \mathrm{kg} /$ week, in $200 \mu \mathrm{l}$, for at least 8 weeks, in adult animals. The drug was diluted 
in warm water from a $50 \mathrm{mg} / \mathrm{ml}$ stock solution in DMSO. In controls, vehicle injections consisted of $200 \mu \mathrm{l}$ of corresponding mixtures of DMSO alone in warm water.

\section{Synaptic function and dopamine transmission}

The surface density of synaptic vesicles and synaptic plasticity were assessed in hippocampal glutamatergic neurons, as in (Andrieux et al 2002). Dopamine transmission was assessed in the nucleus accumbens as in (Brun et al 2005).

\section{Behavioral studies}

In all tests performed, STOP null mice and WT control littermate mice arose from the same colony (F1 generation from BALBc/ 129 SvPas crossing). All experiments were done blind to genotype and to treatment.

Mouse spontaneous activities (feeding, sleeping, grooming, walking or remaining still while awake) were video-recorded over a $3 \mathrm{~h}$ time duration during the night and the number of shifts between activities was determined (Andrieux et al 2002).

The maternal behavior of treated and untreated mice was monitored by assaying the mouse ability to build a nest and to retrieve pups. For assessment of nesting capacity, the tested mouse was placed in a 240 x 240 × 120 mm cage containing litter and provided with a Kleenex tissue folded in 4 (final dimensions, 100 x $100 \mathrm{~mm}$ ). After 60 hours, the mouse ability to use the paper and to build a nest was scored as follows: tissue use (score as follow, 0: the Kleenex tissue remained folded; 1 : the tissue has been unfolded but not shredded; 2: the tissue was shredded), nest building (score as follow, 0: no attempt to build a nest; 1 : primitive flat nest of uncontrolled shape; 2: true nest, the paper is mixed with litter to form a circular nest, less than $80 \mathrm{~mm}$ in diameter). For assessment of retrieving ability, following the nestbuilding test, on day one, each female was exposed to three 1-3-day-old pups. Pups were placed in three corners of the cage distant from the nest. After 30 min the pups were returned to their natural mother. On day two, each female was again exposed to three pups. The 
number of pups retrieved during 30 min by each female was scored. Retrieving was scored as the number of pups retrieved (0 to 3). Finally, a global score for nesting and retrieving capacity (TNR) was determined for each mouse, by adding the tissue use, nest building, and pup retrieving scores (maximal score for TNR is 7).

\section{Results}

\section{Microtubule stabilization by epothilone D in STOP null neurons}

Neuronal microtubules are normally cold stable, due to association with STOP proteins (Guillaud et al 1998) (Figure 1A-B). Microtubule cold stability is thus abolished in STOP deficient neurons (Andrieux et al 2002) (Figure 1C-D). To test the microtubule stabilizing effect of epothilone D, STOP deficient neurons were exposed to various drug concentrations and then either kept at $37^{\circ} \mathrm{C}$ or exposed to the cold for 45 minutes prior to microtubule staining. At subnanomolar concentration of epothilone D, cold exposure induced extensive microtubule disassembly (Figure 1D-E). At 1nM concentration epothilone D induced an apparently complete cold-stabilization of neuronal microtubules (Figure 1F), with no more detectable difference in microtubule signals between cold exposed STOP null neurons and control cells and no further increase in the microtubule signal at higher epothilone D concentrations (Figure 1G-H).

In whole animals, in this study, epothilone D was generally used at a dose of $3 \mathrm{mg} / \mathrm{kg} / \mathrm{week}$, in one intra-peritoneal injection per week. This drug dosage is ten times lower than the dosage routinely used for inhibition of tumor growth in mice (Wang et al 2005), and has been found to yield a brain epothilone concentration in the nanomolar range (Schering AG patent, WO 03/074053 A1, published 12.09.2003).

\section{Synaptic vesicle density}


A striking signature of STOP deficiency is a two fold drop in the average surface density of synaptic vesicle on electron micrographs of hippocampal glutamatergic synapses (Andrieux et al 2002). In addition to its physiological importance, synaptic vesicle density shows little variability between animals of the same genotype and between repeated experiments, and offers thereby a meaningful and sensitive way to detect treatment effects. In this study, epothilone D treatment had no significant effect on the vesicle density in WT mice (Figure 2), but, in contrast, induced a 16\%, highly significant increase of the vesicle density in STOP null mice (Figure 2). In parallel experiments, a long-term neuroleptic treatment (Andrieux et al 2002) induced a 19\% increase in the vesicle density, in STOP null mice (Figure 2).

\section{Synaptic plasticity}

STOP null mice display defects in both short- and long-term synaptic plasticity, including impaired Post-Tetanic Potentiation (PTP), Long-Term Depression (LTD) and Long-Term Potentiation (LTP) in the CA1 region of the hippocampus (Andrieux et al 2002). Neuroleptic treatment restores PTP in STOP null mice, in the absence of significant influence on LTP (Andrieux et al 2002). In the present study, epothilone D treatment improved significantly both PTP and LTP in STOP null mice (Figure 3A-B). In LTP experiments, the restoration of synaptic potentiation by epothilone $\mathrm{D}$ treatment was evident at $60 \mathrm{~min}$ and persisted at subsequent time points (up to $120 \mathrm{~min}$, Figure 3B). In contrast, no significant effect of the treatment was observed for LTD (Figure 3C). In WT animals, synaptic plasticity was not significantly affected by epothilone D treatment (Figure 3, A-C). Thus, epothilone D treatment improves both PTP and LTP in STOP null mice, and does not detectably affect synaptic plasticity in WT animals.

\section{Dopamine transmission}


In STOP null mice, dopaminergic neurons in the nucleus accumbens (Nacc) exhibit a dopaminergic hyper-reactivity, with a conspicuous augmentation of dopamine efflux evoked by electrical stimulations, compared to WT neurons (Brun et al 2005). In the present study, dopamine effluxes were abnormally high in $\mathrm{WT}$ animals, most probably due to the stress generated by weekly injections (Pani et al 2000). In our experimental conditions, the dopamine response was unaffected by epothilone D treatment in both WT and STOP null mice (Figure 4).

\section{Behavioral analysis}

STOP null mice display a complex set of behavioral disorders several of which, such as anxiety or locomotor activity, proved hard to test on animals stressed by weekly injections. In this study, we used both an analysis of spontaneous activity, and an analysis of maternal behavior, which was not detectably perturbed by injections.

Mouse spontaneous activity is disorganized in STOP null mice, with an increased frequency of shifts between different spontaneous activities, such as feeding, walking, remaining still without sleeping, sleeping and grooming (Andrieux et al 2002). Epothilone D treatment induced a significant decrease in the frequency of shifts between activities in STOP null mice, in the absence of significant effects in WT animals (Figure 5A).

STOP null mice display severe maternal defects, which are of behavioral origin, which affect tasks such as nest building or pup retrieving, and which we have previously used as endpoints for assessment of drug effects (Andrieux et al 2002). When given paper tissue, WT nulliparous females first shred the tissue and then use the shredded tissue to build a nest. When properly trained and presented with pups, such mice are also capable to retrieve pups. We scored mouse ability to process tissue (T), to use the tissue to build a nest (N) and to retrieve pups (R). The three scores were added to determine a global maternal ability score 
(TNR). WT mice had, as expected, good maternal skills in these tests, and their performances were unaltered by epothilone D treatment (Figure 5B). In contrast, vehicle alone treated STOP null mice were conspicuously incompetent in maternal tasks (Figure 5B). The standard treatment with $3 \mathrm{mg} / \mathrm{kg} /$ week induced a remarkable improvement of maternal behavior in STOP null mice, with a highly significant increase in the global maternal ability score (Figure 5B). Epothilone D was still fully efficient at a $0.3 \mathrm{mg} / \mathrm{kg} /$ week, whereas drug effects were barely detectable at $0.03 \mathrm{mg} / \mathrm{kg} /$ week.

Nurturing deficits invariably lead to pup death in the offspring of STOP null mice (Andrieux et al 2002). In a previous study, long-term neuroleptic treatment improved the maternal skills of some STOP null mothers to an extent sufficient to allow pup survival (Andrieux et al 2002). Here, in 17 vehicle alone treated STOP-null females, no pup survival was observed, in agreement with previous observations made on dozens of STOP null females and hundreds of pups (Andrieux et al 2002). In contrast, pup survival was observed in the offspring of 5 out of 15 STOP null mice treated with epothilone D. In two cases, the amelioration of maternal skills was truly remarkable, with a survival of all the pups from the litter (7/7 and 6/6).

\section{Drug tolerance}

Although a systematic study of drug tolerance would be beyond the scope of our work, we have checked for possible obvious side effects of epothilone D in WT animals. The longest followed animals were three females, injected with $3 \mathrm{mg} / \mathrm{kg} /$ week for 15 months. These animals showed no obvious behavioral or anatomical anomalies. A group of 48 females treated with $3 \mathrm{mg} / \mathrm{kg} /$ week of epothilone D followed for 4-8 months showed no obvious anomalies. To test for a possible deleterious effect of epothilone D on female fertility and development, we monitored WT females exposed either to $0.3 \mathrm{mg} / \mathrm{kg} /$ week epothilone D or to 
vehicle alone, for a 5 month time period during which they were mated and underwent pregnancy ( $\mathrm{n}=7$, in each group). All females gave birth to apparently normal pups, which later developed normally. The number of pups per mother in the epothilone treated group (5.6 \pm 0.72) was similar to that observed in the vehicle alone injected group (5.00 \pm 1.03$)$. These results indicate an absence of obvious deleterious effect of epothilone D treatment on mouse embryonic development, viability or fertility, at the doses used in this study.

\section{Discussion}

Microtubules are major components of neurons. Since synaptic plasticity depends on microtubule functions (Dillon and Goda 2005; Okamoto et al 2004; Zito et al 2004) a role of microtubules in synaptic transmission and hence in mental functions has long been suspected (van Rossum and Hanisch 1999), but not firmly demonstrated. However, convergent evidence for a role of the cytoskeleton in mental illnesses has arisen recently, with the discovery of a cytoskeletal role for DISC1, a schizophrenia susceptibility gene (Callicott et al 2005; Morris et al 2003; Owen et al 2005a) and of a function in the synapse organization for other genes involved in schizophrenia (Harrison and Owen 2003; Harrison and Weinberger 2005; Owen et al 2005a; Owen et al 2005b; Petryshen et al 2005; Stefansson et al 2004) or in other severe mental pathologies (Chubykin et al 2005; Jamain et al 2003; Laumonnier et al 2004; Yan et al 2005). Our work with STOP null mice (Andrieux et al 2002) has demonstrated that alterations of a microtubule effector could generate a "disease of the synapse” (Mirnics et al 2001) with a set of neurotransmission defects considered as central to mental diseases such as schizophrenia (Frankle et al 2003), associated with schizophrenic-related behavioral disorders. Finally, very recently, the deletion of the cytoskeletal protein Stathmin has been shown to induce behavioral disorder in mice (Shumyatsky et al 2005). Our present 
demonstration that a microtubule stabilizer can amend synaptic defects and can improve dramatically behavior in STOP null mice, adds strong evidence for an important role of microtubules in synaptic modulation and in mental functions.

The positive influence of epothilone $\mathrm{D}$ on synaptic plasticity and behavior raises many challenging questions. The most obvious ones concern the relationship between microtubule stabilization and the drug effects. In the present study, we find that nanomolar concentrations of epothilone D are sufficient to rescue microtubule cold-stability in STOP deficient neurons, in vitro. Nanomolar concentrations of epothilones have previously been shown to stabilize microtubule dynamics in different cell types, presumably due to strong accumulation of the drugs inside cells (Chou et al 1998; Hofle and Reichenbach 2005). Such nanomolar epothilone concentrations also correspond to the range of brain drug concentrations observed in mice, in treatment conditions close to ours (3mg/kg) (Schering AG patent, WO 03/074053 A1, published 12.09.2003). Thus, with rough estimates, there is no major incompatibility between in vitro and in vivo data with regard to epothilone effects. Progress in microscopy technology may allow in a foreseeable future, direct studies of microtubule dynamics during synaptic activation, and of the influence of microtubule dynamics on the size of vesicle pools and on synaptic plasticity, both in normal conditions and in the presence of epothilone D. In STOP null mice, the effects of epothilone D on behavior are reminiscent of those of a chronic neuroleptic treatment. Additionally, in agreement with previous studies (Konradi and Heckers 2001), we find that neuroleptics are able to rescue synaptic plasticity (Andrieux et al 2002) and synaptic vesicle pools (this study) in glutamatergic neurons, as epothilone D. However, whereas neuroleptics are thought to act principally as dopamine blockers, epothilone D had no detectable effect on dopamine transmission, in our treatment conditions. Thus, a long-term epothilone D or neuroleptic treatments may act through distinct pathways 
and an association of neuroleptic and epothilone D may turn out to be more efficient than each drug used alone.

The lack of effect of epothilone D on dopaminergic efflux observed in this study whereas the drug apparently ameliorates glutamatergic transmission may mean that hyper-dopaminergy is not a direct result of hypo-glutamatergy in STOP null mice. However, such a conclusion could be premature, since, in our study context, dopamine transmission is most probably affected by the chronic stress induced by the repeated intra-peritoneal injections used for long-term epothilone treatment (Pani et al 2000; Thompson et al 2004).

We have chosen epothilone D among available epothilones because it has less toxicity at efficient doses than other epothilones and because it accumulates in brain tissues upon chronic administration (Hofle and Reichenbach 2005). In our experience, epothilone D could be used at low doses provided that treatment duration was sufficient and we believe that this was a key factor for success. We have done some attempts with epothilone $\mathrm{B}$, but in this case, there was an apparent overlap between toxic doses and effective doses. Although there is little left unknown about the molecular targets of epothilones whose complex with tubulin has been crystallized (Nettles et al 2004) it will obviously be interesting to find compounds other than epothilone D with similar activity on synaptic transmission and on behavior. Epothilone research is currently very active, and new compounds with similar pharmacological profile as epothilone D will undoubtedly be available in the near future.

Is the beneficial effect of epothilone D on behavioral disorders special to STOP null mice, which are deficient for a microtubule effector, or will they be observed in other animal models of mental diseases? Tests of epothilone D in different animal models will tell whether modifying microtubule dynamics can have a favorable effect even in models not directly involving cytoskeletal molecules. With respect to human schizophrenia, at least a subclass of 
cases may involve the cytoskeleton directly (Owen et al 2005a) or indirectly, and may thereby benefit from epothilone D treatment.

In conclusion, the beneficial effect of epothilone D treatment on synaptic transmission and behavior observed in an animal model of schizophrenia suggests that microtubules or microtubule effectors represent useful novel targets for anti-psychotic agents. Epothilone D is already validated for human use and data should be available concerning its possible side effects in humans at the low doses required for psychotropic effects. Therefore, testing epothilone D in schizophrenic patients or in patients with other mental diseases thought to result from neuronal connectivity defects may turn out to be feasible in the near future.

Acknowledgments: We thank D. Proietto for technical help, Dr J.M. Danion for helpful discussion, Dr C. Bosc for discussion and support. 
Andrieux, A., Salin, P.A., Vernet, M., Kujala, P., Baratier, J., Gory-Faure, S., Bosc, C., Pointu, H., Proietto, D., Schweitzer, A., Denarier, E., Klumperman, J., Job, D. (2002): The suppression of brain cold-stable microtubules in mice induces synaptic defects associated with neuroleptic-sensitive behavioral disorders. Genes Dev 16:2350-64.

Bosc, C., Andrieux, A., Job, D. (2003): STOP proteins. Biochemistry 42:12125-32.

Bosc, C., Cronk, J.D., Pirollet, F., Watterson, D.M., Haiech, J., Job, D., Margolis, R.L. (1996): Cloning, expression, and properties of the microtubule-stabilizing protein STOP. Proc Natl Acad Sci U S A 93:2125-30.

Brun, P., Begou, M., Andrieux, A., Mouly-Badina, L., Clerget, M., Schweitzer, A., Scarna, H., Renaud, B., Job, D., Suaud-Chagny, M.F. (2005): Dopaminergic transmission in STOP null mice. J Neurochem 94:63-73.

Callicott, J.H., Straub, R.E., Pezawas, L., Egan, M.F., Mattay, V.S., Hariri, A.R., Verchinski, B.A., Meyer-Lindenberg, A., Balkissoon, R., Kolachana, B., Goldberg, T.E., Weinberger, D.R. (2005): Variation in DISC1 affects hippocampal structure and function and increases risk for schizophrenia. Proc Natl Acad Sci U S A 102:8627-32.

Chou, T.C., Zhang, X.G., Balog, A., Su, D.S., Meng, D., Savin, K., Bertino, J.R., Danishefsky, S.J. (1998): Desoxyepothilone B: an efficacious microtubule-targeted antitumor agent with a promising in vivo profile relative to epothilone B. Proc Natl Acad Sci U S A 95:9642-7.

Chubykin, A.A., Liu, X., Comoletti, D., Tsigelny, I., Taylor, P., Sudhof, T.C. (2005): Dissection of synapse induction by neuroligins: effect of a neuroligin mutation associated with autism. J Biol Chem 280:22365-74.

Dillon, C., Goda, Y. (2005): The actin cytoskeleton: integrating form and function at the synapse. Annu Rev Neurosci 28:25-55.

Dotti, C.G., Sullivan, C.A., Banker, G.A. (1988): The establishment of polarity by hippocampal neurons in culture. J Neurosci 8:1454-68.

Fradley, R.L., O'Meara G, F., Newman, R.J., Andrieux, A., Job, D., Reynolds, D.S. (2005): STOP knockout and NMDA NR1 hypomorphic mice exhibit deficits in sensorimotor gating. Behav Brain Res 163:257-64.

Frankle, W.G., Lerma, J., Laruelle, M. (2003): The synaptic hypothesis of schizophrenia. Neuron 39:205-16.

Guillaud, L., Bosc, C., Fourest-Lieuvin, A., Denarier, E., Pirollet, F., Lafanechere, L., Job, D. (1998): STOP proteins are responsible for the high degree of microtubule stabilization observed in neuronal cells. J Cell Biol 142:167-79.

Hardt, I.H., Steinmetz, H., Gerth, K., Sasse, F., Reichenbach, H., Hofle, G. (2001): New natural epothilones from Sorangium cellulosum, strains So ce90/B2 and So ce90/D13: isolation, structure elucidation, and SAR studies. J Nat Prod 64:847-56.

Harrison, P.J., Owen, M.J. (2003): Genes for schizophrenia? Recent findings and their pathophysiological implications. Lancet 361:417-9.

Harrison, P.J., Weinberger, D.R. (2005): Schizophrenia genes, gene expression, and neuropathology: on the matter of their convergence. Mol Psychiatry 10:804.

Hofle, G., Reichenbach, H. (2005): Epothilone, a Myxobacterial metabolite with promising antitumor activity, CRC Press ed. Boca Raton, FL, pp 413-449.

Jamain, S., Quach, H., Betancur, C., Rastam, M., Colineaux, C., Gillberg, I.C., Soderstrom, H., Giros, B., Leboyer, M., Gillberg, C., Bourgeron, T. (2003): Mutations of the Xlinked genes encoding neuroligins NLGN3 and NLGN4 are associated with autism. Nat Genet 34:27-9. 
Kolman, A. (2004): BMS-310705 Bristol-Myers Squibb/GBF. Curr Opin Investig Drugs 5:1292-7.

Konradi, C., Heckers, S. (2001): Antipsychotic drugs and neuroplasticity: insights into the treatment and neurobiology of schizophrenia. Biol Psychiatry 50:729-42.

Laumonnier, F., Bonnet-Brilhault, F., Gomot, M., Blanc, R., David, A., Moizard, M.P., Raynaud, M., Ronce, N., Lemonnier, E., Calvas, P., Laudier, B., Chelly, J., Fryns, J.P., Ropers, H.H., Hamel, B.C., Andres, C., Barthelemy, C., Moraine, C., Briault, S. (2004): X-linked mental retardation and autism are associated with a mutation in the NLGN4 gene, a member of the neuroligin family. Am J Hum Genet 74:552-7.

Mirnics, K., Middleton, F.A., Lewis, D.A., Levitt, P. (2001): Analysis of complex brain disorders with gene expression microarrays: schizophrenia as a disease of the synapse. Trends Neurosci 24:479-86.

Morris, J.A., Kandpal, G., Ma, L., Austin, C.P. (2003): DISC1 (Disrupted-In-Schizophrenia 1 ) is a centrosome-associated protein that interacts with MAP1A, MIPT3, ATF4/5 and NUDEL: regulation and loss of interaction with mutation. Hum Mol Genet 12:1591608.

Nettles, J.H., Li, H., Cornett, B., Krahn, J.M., Snyder, J.P., Downing, K.H. (2004): The binding mode of epothilone A on alpha,beta-tubulin by electron crystallography. Science 305:866-9.

Okamoto, K., Nagai, T., Miyawaki, A., Hayashi, Y. (2004): Rapid and persistent modulation of actin dynamics regulates postsynaptic reorganization underlying bidirectional plasticity. Nat Neurosci 7:1104-12.

Owen, M.J., Craddock, N., O'Donovan M, C. (2005a): Schizophrenia: genes at last? Trends Genet 21:518-25.

Owen, M.J., O'Donovan, M.C., Harrison, P.J. (2005b): Schizophrenia: a genetic disorder of the synapse? BMJ 330:158-9.

Pani, L., Porcella, A., Gessa, G.L. (2000): The role of stress in the pathophysiology of the dopaminergic system. Mol Psychiatry 5:14-21.

Petryshen, T.L., Middleton, F.A., Kirby, A., Aldinger, K.A., Purcell, S., Tahl, A.R., Morley, C.P., McGann, L., Gentile, K.L., Rockwell, G.N., Medeiros, H.M., Carvalho, C., Macedo, A., Dourado, A., Valente, J., Ferreira, C.P., Patterson, N.J., Azevedo, M.H., Daly, M.J., Pato, C.N., Pato, M.T., Sklar, P. (2005): Support for involvement of neuregulin 1 in schizophrenia pathophysiology. Mol Psychiatry 10:366-74, 328.

Schultz, S.K., Andreasen, N.C. (1999): Schizophrenia. Lancet 353:1425-30.

Shumyatsky, G.P., Malleret, G., Shin, R.M., Takizawa, S., Tully, K., Tsvetkov, E., Zakharenko, S.S., Joseph, J., Vronskaya, S., Yin, D., Schubart, U.K., Kandel, E.R., Bolshakov, V.Y. (2005): stathmin, a gene enriched in the amygdala, controls both learned and innate fear. Cell 123:697-709.

Stefansson, H., Steinthorsdottir, V., Thorgeirsson, T.E., Gulcher, J.R., Stefansson, K. (2004): Neuregulin 1 and schizophrenia. Ann Med 36:62-71.

Thompson, J.L., Pogue-Geile, M.F., Grace, A.A. (2004): Developmental pathology, dopamine, and stress: a model for the age of onset of schizophrenia symptoms. Schizophr Bull 30:875-900.

van Rossum, D., Hanisch, U.K. (1999): Cytoskeletal dynamics in dendritic spines: direct modulation by glutamate receptors? Trends Neurosci 22:290-5.

Wang, H., Wang, Z., Wang, S., Li, M., Nan, L., Rhie, J.K., Covey, J.M., Zhang, R., Hill, D.L. (2005): Preclinical pharmacology of epothilone D, a novel tubulin-stabilizing antitumor agent. Cancer Chemother Pharmacol 56:255-60.

Yan, J., Oliveira, G., Coutinho, A., Yang, C., Feng, J., Katz, C., Sram, J., Bockholt, A., Jones, I.R., Craddock, N., Cook, E.H., Jr., Vicente, A., Sommer, S.S. (2005): Analysis of the 
neuroligin 3 and 4 genes in autism and other neuropsychiatric patients. Mol Psychiatry 10:329-32.

Zito, K., Knott, G., Shepherd, G.M., Shenolikar, S., Svoboda, K. (2004): Induction of spine growth and synapse formation by regulation of the spine actin cytoskeleton. Neuron 44:321-34. 


\section{Figure legends}

\section{Figure 1: Microtubule stability}

Analysis of microtubule cold stability in primary cultures of neuronal cells from wild type (AB) and STOP deficient embryos $(\mathrm{C}-\mathrm{H})$ in the presence or not of various amount of Epothilone D. Cells were either maintained at $37^{\circ} \mathrm{C}$ or exposed to the cold $\left(0^{\circ} \mathrm{C}\right.$ for $\left.45 \mathrm{~min}\right)$. Following free tubulin extraction by cell permeabilization, microtubules were stained with anti $\alpha$-tubulin (green) and nuclei were stained with Hoescht 33258 (blue).

\section{Figure 2: Analysis of the surface density of synaptic vesicles}

Synaptic vesicle density, calculated as the ratio of the number of vesicles/nerve terminal surface (after subtraction of the surface area occupied by mitochondria). Results are shown as means +/- s.e.m. Treatments and genotypes were as indicated. In epothilone experiments, 75 measurements from five mice, in each treatment and genotype group were performed. In neuroleptic experiments, 150 measurements from three animals were performed in each treatment group. $* * * p<0.001$, t-test.

\section{Figure 3: Quantitative analysis of synaptic plasticity in CA1 region of hippocampus}

Averaged responses are shown in the two left panels and computed results are illustrated in the right panels. Genotypes and treatments, as indicated.

A. PTP (Post-tetanic potentiation) of Schaffer collateral synaptic transmission. At time 0 a high-frequency stimulation (100 Hz, $1 \mathrm{sec})$ of Schaffer collaterals was applied in the presence of the NMDA antagonist D-APV (50-100 $\mu \mathrm{M})$. Left panels: summary of PTP experiments in Epothilone D treated and untreated WT and STOP null mice. Right panel: average responses 
0-30 sec after tetanus, showing no modification of potentiation in treated WT mice $(n=7)$ versus untreated WT mice $(n=8)$ whereas a significant increase of potentiation was observed in treated STOP null mice $(n=7)$ versus untreated STOP null mice $(n=8)$.

B: LTP experiments at the Schaffer collateral-CA1 pyramidal cell synapses. A high-frequency stimulation (four tetani of $100 \mathrm{~Hz}$, duration 1 sec stimuli, given $20 \mathrm{sec}$ apart) was done at time 0. Initial EPSP slopes were normalized in each experiment using the averaged slope value during the control period (-10 to 0 min). Left panels: summary of LTP experiments (mean \pm s.e.m.) done in epothilone D treated and untreated WT or STOP null mice. Right panel: results computed at 50-60 min after tetanus showed no significant modifications of potentiation in treated WT mice $(n=9)$ compared to untreated mice $(n=6)$ whereas a significant increase of the potentiation was observed in treated STOP null mice $(n=8)$ compare to untreated mice $(\mathrm{n}=9)$. Results computed at $110-120$ min also showed a significant increase of the potentiation in treated STOP null mice $(n=8)$ compare to untreated mice $(n=8)$.

C: LTD experiments at the Schaffer collateral-CA1 pyramidal cell synapses. At time 0 , a lowfrequency stimulation (1 Hz, $15 \mathrm{~min})$ of Schaffer collaterals was applied. Right panels, summary of LTD experiments in epothilone D treated and untreated WT or STOP null mice. Right panel, results computed at 50-60 min after stimulus showed no significant modifications of LTD in WT treated mice $(n=6)$ versus untreated mice $(n=8)$ or in treated STOP null mice $(n=5)$ versus untreated mice $(n=6)$.

${ }^{*} p<0.05, * * p<0.02$, t test.

\section{Figure 4: Effect of epothilone D on evoked dopamine efflux}

DA effluxes in response to electrical stimulations were measured by differential pulse amperometry in the nucleus accumbens of WT or STOP null mice (STOP KO), treated either 
with vehicle alone or with epothilone D. Electrical stimulations, applied in the ascending DA pathway, consisted of 200 pulses with a regular pattern, at various frequencies as indicated. The effect of stimulation frequency is presented as mean absolute values \pm s.e.m. of the maximal evoked DA efflux changes ( $n=8-10$ in each group). The DA response was not affected by epothilone D in either WT or STOP null mice ( $p>0.05$, at all time points, t test).

\section{Figure 5: Behavioral studies}

A: Mouse activities. Spontaneous mice activities (sleeping, feeding, grooming, walking and remaining while awake) were video-recorded during $3 \mathrm{~h}$, in WT or STOP null mice (STOP KO) treated either with epothilone D ( Epo D 3mg/kg/week) or with vehicle alone. The number of occurrences of each activity was determined for each mouse and averaged: WT vehicle $n=29$ (12 males and 17 females), WT Epo D $n=33$ (12 males and 21 females), STOP KO vehicle $\mathrm{n}=28$ (12 males and 16 females), STOP KO Epo D n = 33 (12 males and 21 females). Each block corresponds to an activity as indicated. Results were similar in males and in females and were pooled for analysis.

B: Maternal behavior. The nurturing ability of WT and STOP null mice (STOP KO) either treated with Epothilone D, at different concentrations or with vehicle alone was assessed (see material and methods). Score ranges were $0-2$ for tissue use (T), 0-2 for nest building (N), 0-3 for the number of retrieved pups (R), and 0-7 for the global nurturing score (TNR). TNR were calculated for each mouse and averaged ( $\mathrm{n}=17$ for all groups). Each block represents a maternal skill, as indicated.

${ }^{*} p<0.05,{ }^{* *} p<0.01, * * * p<0.001$, non parametric Mann and Whitney U test 
Figure 1

WT neuron
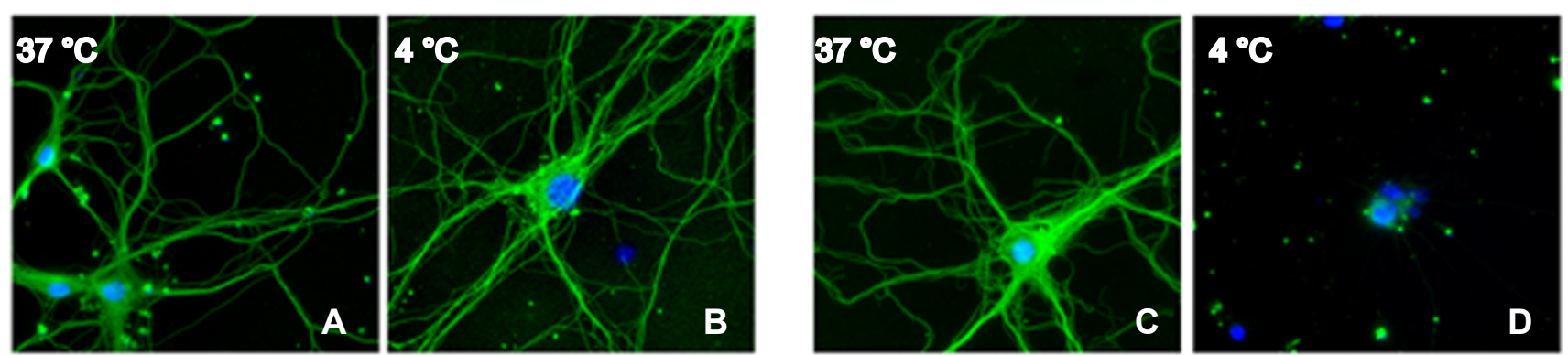

STOP KO neurons
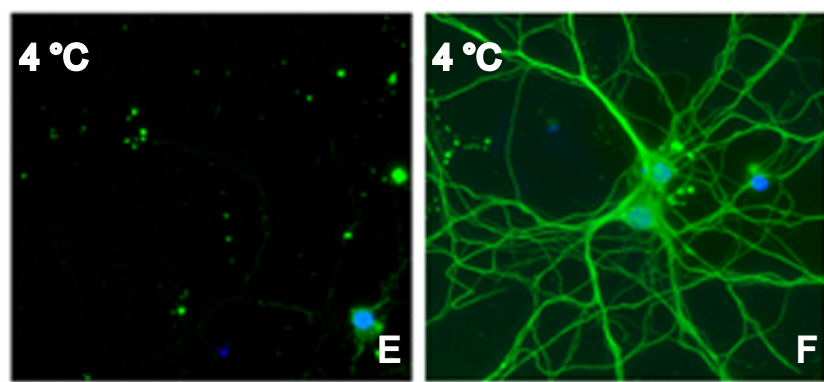

Epo D 1 nM

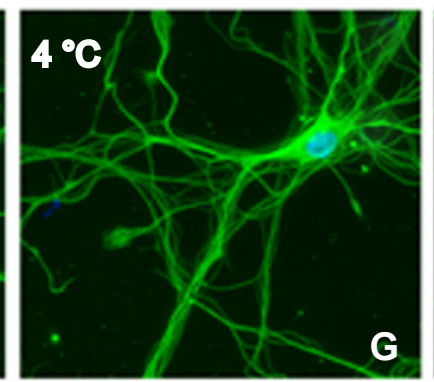

Epo D 10 nM

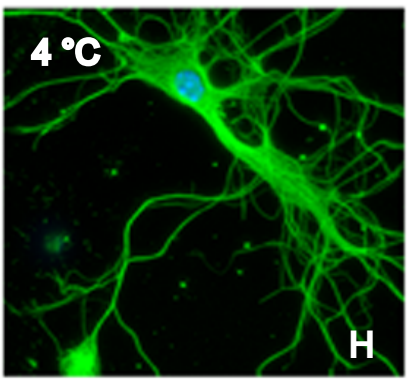

Epo D 100 nM 
Figure 2

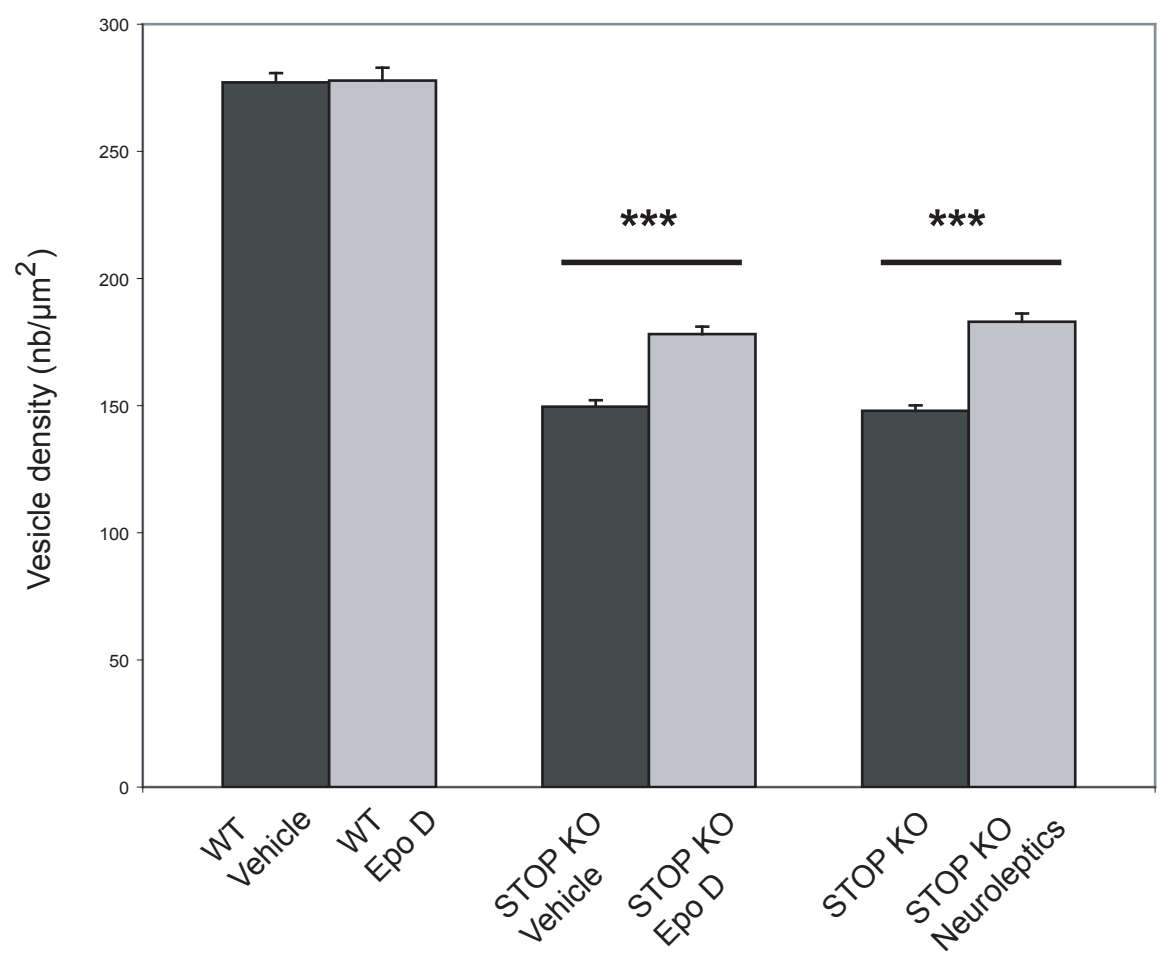




\section{Figure 3}

A

- WTEpo D

- WT Vehicle

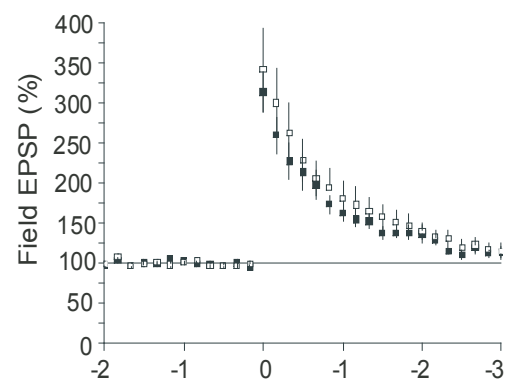

B

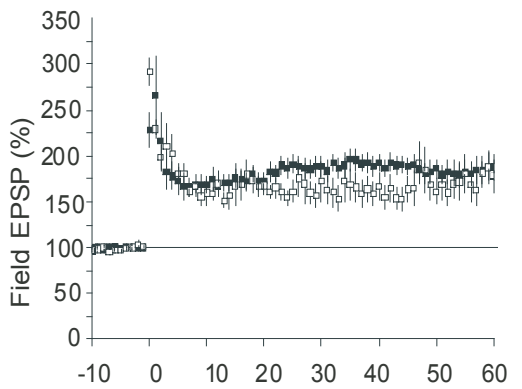

C

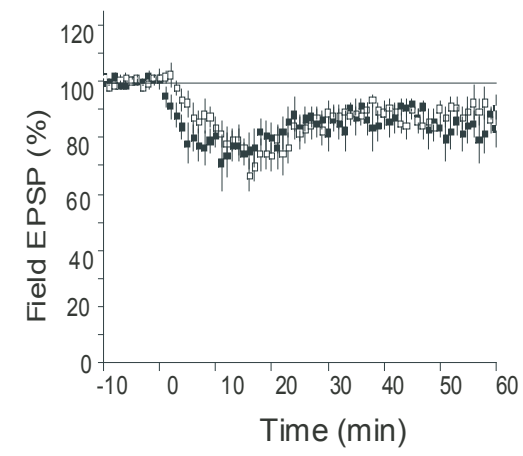

- STOP KO Epo D

STOP KO Vehicle
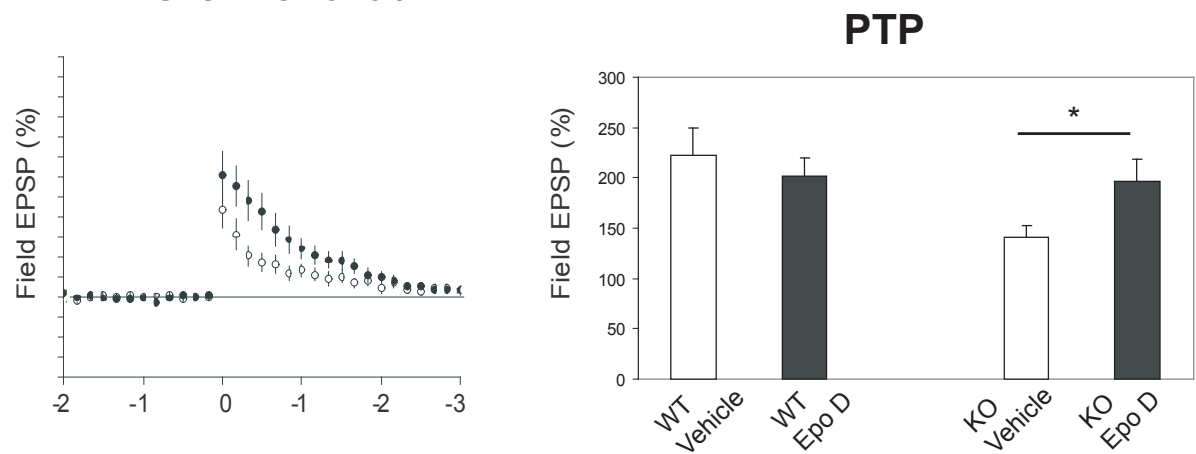

LTP
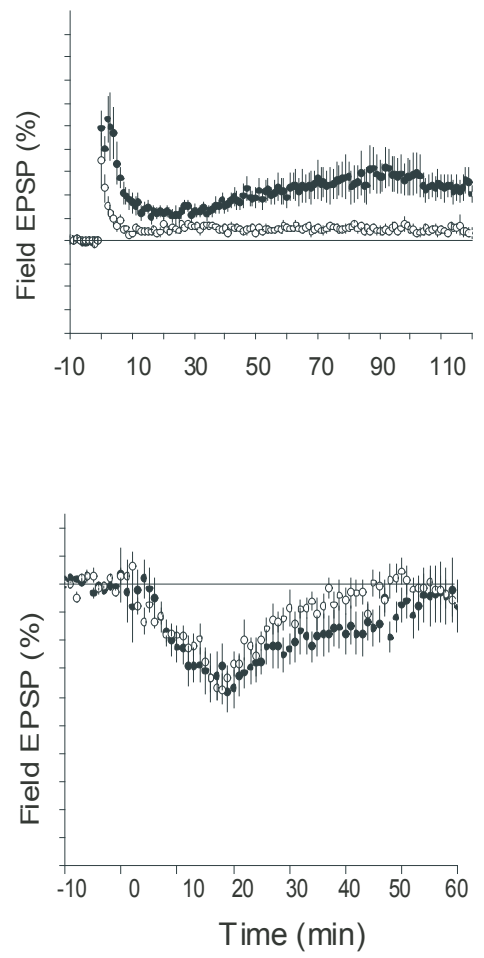

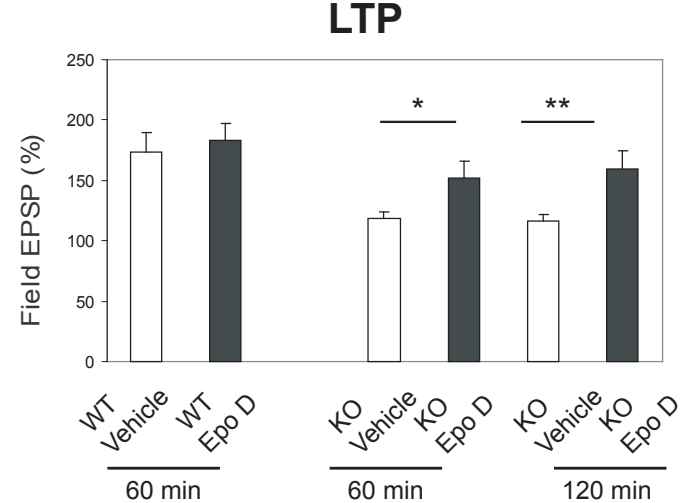

LTD

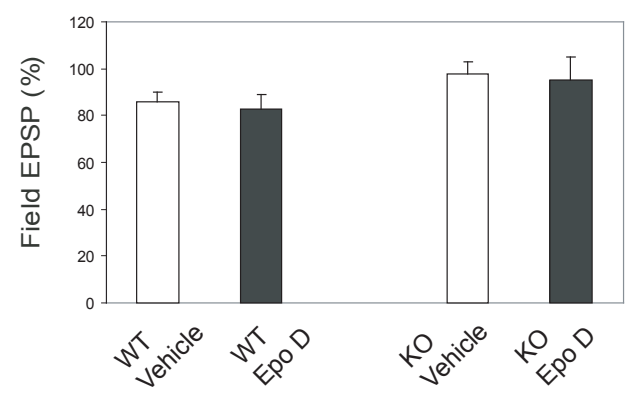


Figure 4
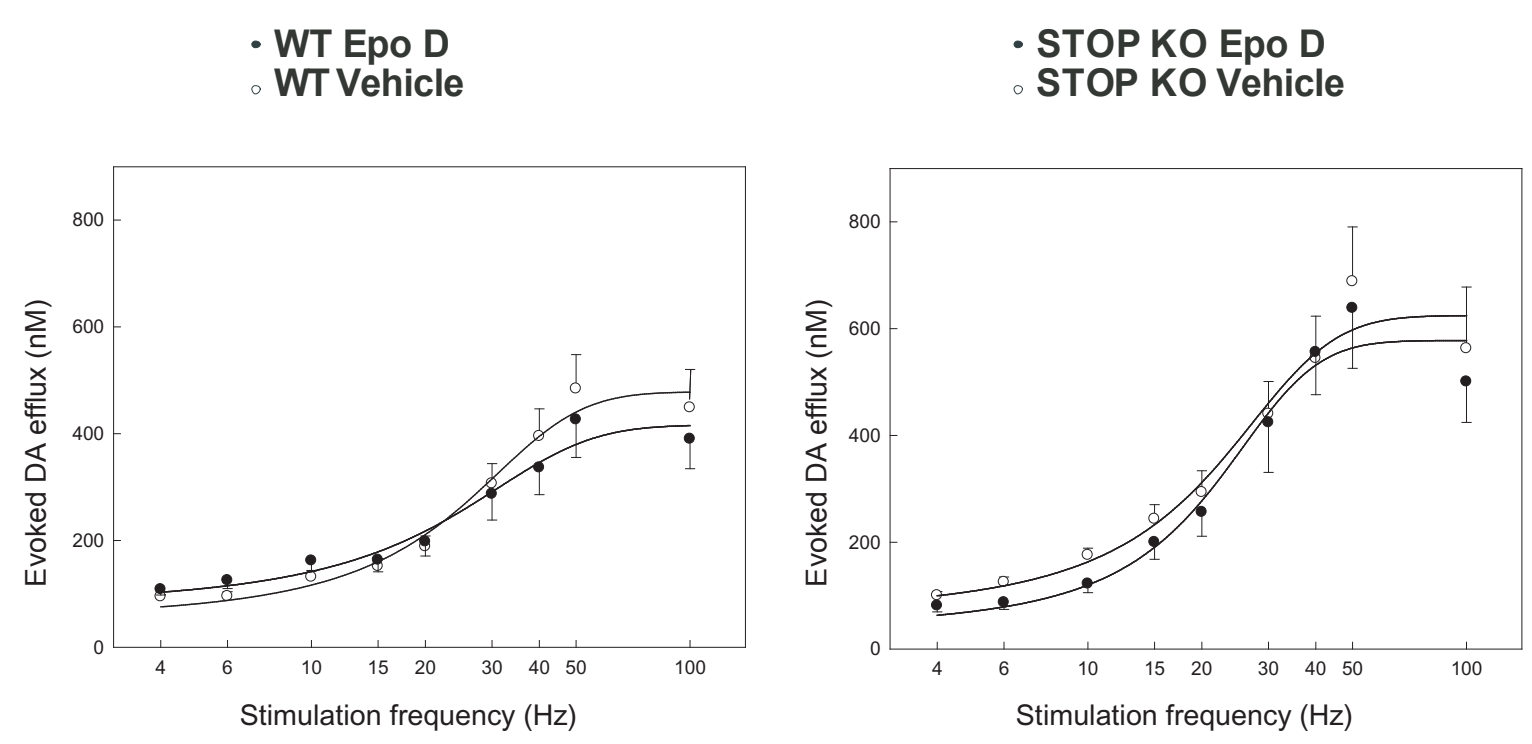
Figure 5

A Mouse activities

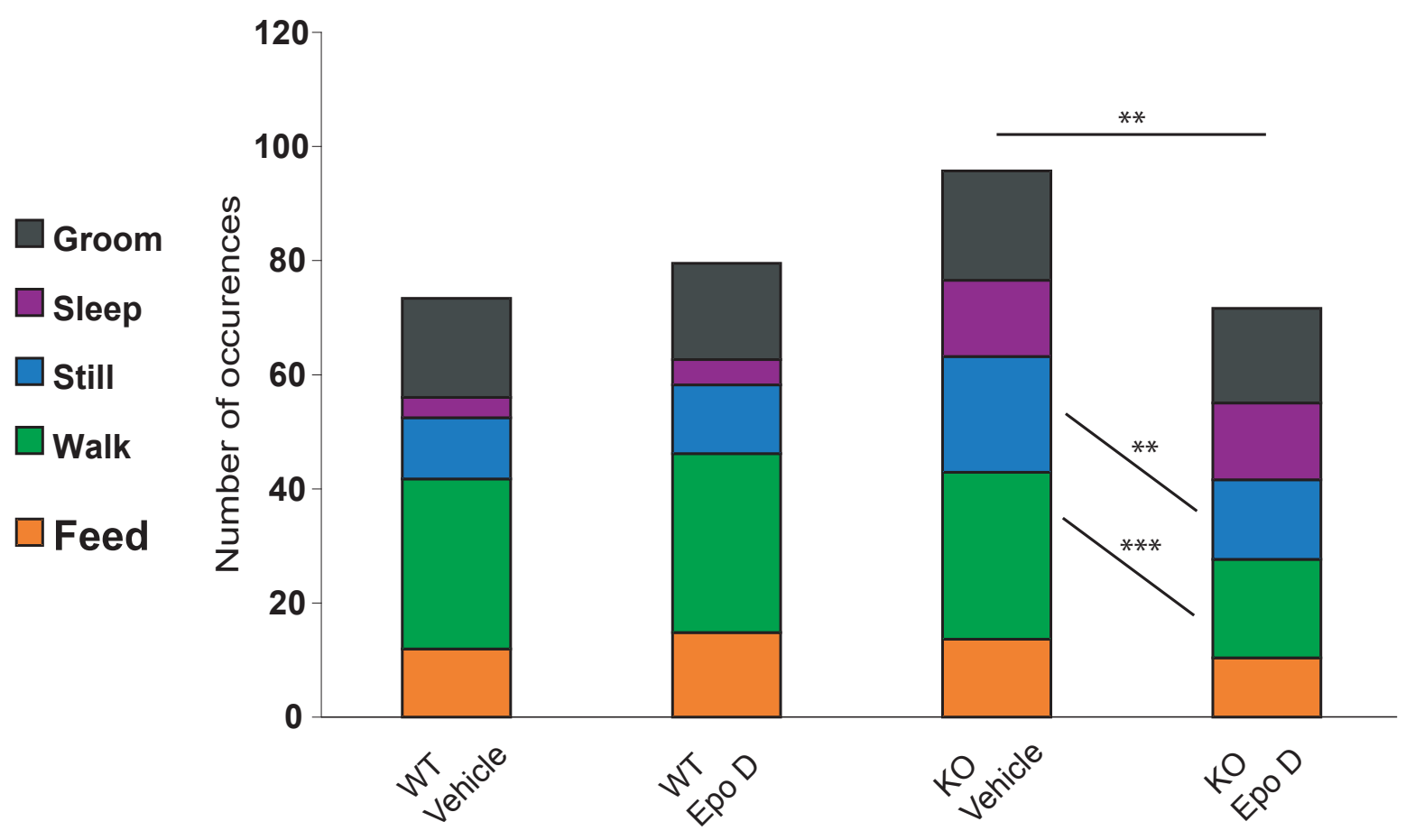

B Maternal behavior

$\square$ Tissue use $\square$ Nest building $\square$ Retrieving

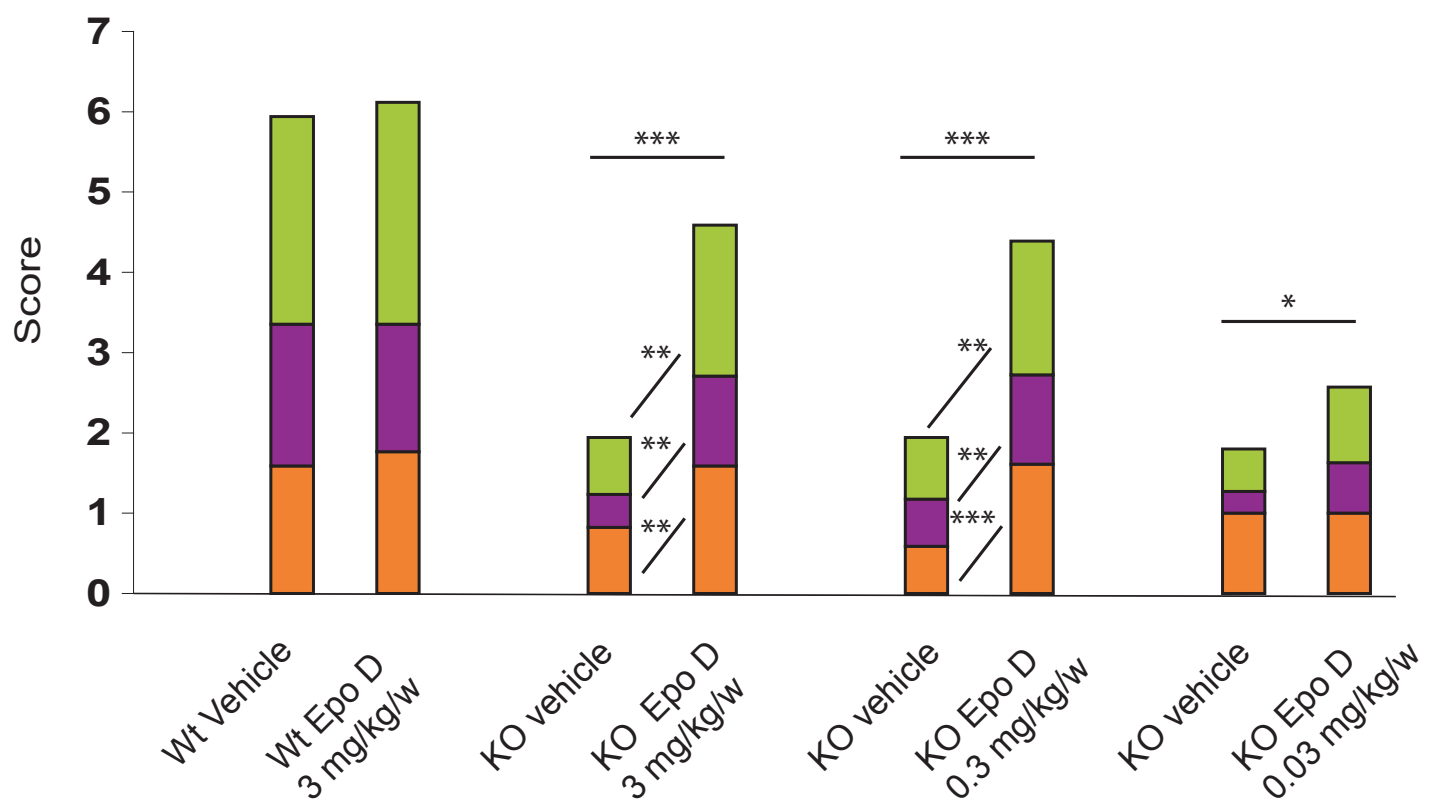

